\title{
Comparative efficiency analysis for silicon, silicon carbide MOSFETs and IGBT device for DC-DC boost converter
}

\author{
Mohd Alam $^{1}$ (1) $\cdot$ Kuldeep Kumar $^{1} \cdot$ Viresh Dutta $^{1}$
}

Received: 20 September 2019 / Accepted: 23 November 2019 / Published online: 27 November 2019

(c) Springer Nature Switzerland AG 2019

\begin{abstract}
In present study, a comparative efficiency analysis for silicon ( $\mathrm{Si}$ ), silicon carbide ( $\mathrm{SiC}$ ) metal oxide semiconductor field effect transistors (MOSFETs) and insulated gate bipolar transistor (IGBT) device based DC-DC boost converter is performed. Due to different gate-drive characteristics of power semiconductor devices such as Si, SiC MOSFETs and IGBT device, different voltage levels are required to drive aforementioned devices. A $500 \mathrm{~W}$ boost converter for wide input voltage range (30-72 V) and $110 \mathrm{~V}$ output voltage is designed having a single gate driver circuit for $\mathrm{Si}$, SiC MOSFETs and IGBT. A single gate driver provides the gate-source (or base-emitter in case of IGBT) signal for all the devices which eliminates the use of separate gate driver circuit. Si MOSFET and IGBT are driven by $12 \mathrm{~V}$ gate-source voltage whereas $\mathrm{SiC}$ MOSFET is operated by $18 \mathrm{~V}$ gate-source voltage using the gate driver circuit. An experimental study is performed for the comparative efficiency analysis for Si, SiC MOSFETs and IGBT device based converter for 20 and $50 \mathrm{kHz}$ switching frequencies. It is found that $\mathrm{SiC}$ based converter provides highest efficiency $\approx 97.8 \%$, whereas the lowest efficiency $\approx 94 \%$ is found for IGBT based converter at $20 \mathrm{kHz}$ switching frequency. SiC based converter gives higher efficiency because lower conduction loss owning to lower on-state resistance as compared to Si MOSFET. Besides this, SiC application has another advantage such as low switching loss at higher frequency resulting compact size of converter. However, use of IGBT at higher switching frequency results in higher switching losses, hence lower efficiency of the converter.
\end{abstract}

Keywords DC-DC boost converter · Efficiency comparison · IGBT · Silicon (Si) · Silicon carbide (SiC)

$\begin{array}{ll}\text { List of symbols } \\ E_{\text {on,IGBT }} & \text { IGBT on state energy loss }(\mathrm{J}) \\ E_{\text {off }, I G B T} & \text { IGBT off state energy loss }(\mathrm{J}) \\ E_{\text {on,M }} & \text { MOSFET on state energy loss }(\mathrm{J}) \\ E_{\text {off,M }} & \text { MOSFET off state energy loss }(\mathrm{J}) \\ E S R & \text { Effective series resistance }(\Omega) \\ f_{S W} & \text { Switching frequency }(\mathrm{kHz}) \\ I_{C} & \text { Collector current }(\mathrm{A}) \\ I_{C a v} & \text { Average collector current }(\mathrm{A}) \\ I_{C r m s} & \text { Collector rms current }(\mathrm{A}) \\ i_{D} & \text { Drain current }(\mathrm{A}) \\ I_{\text {Drms }} & \text { Drain rms current (A) } \\ I_{\text {Lrms }} & \text { Inductor rms current }(\mathrm{A}) \\ I_{O} & \text { Output current }(\mathrm{A})\end{array}$

List of symbols

$E_{\text {on,IGBT }} \quad$ IGBT on state energy loss $(\mathrm{J})$

$E_{\text {off,IGBT }}$ IGBT off state energy loss (J)

$E_{\text {on, } M} \quad$ MOSFET on state energy loss $(\mathrm{J})$

$E_{\text {off }, M} \quad$ MOSFET off state energy loss (J)

ESR Effective series resistance $(\Omega)$

$f_{s w} \quad$ Switching frequency $(\mathrm{kHz})$

$i_{C} \quad$ Collector current (A)

ICav

ICrms

$i_{D}$

IDrms

$I_{\text {Lrm }}$

$\triangle$ Mohd Alam, gbpec.mohd.alam@gmail.com; Kuldeep Kumar, kuldeepnitb@gmail.com; Viresh Dutta, viresh
${ }^{1}$ Photovoltaic Laboratory, Centre for Energy Studies, Indian Institute of Technology Delhi, Delhi 110016, India.
$P_{\text {con,D }} \quad$ Diode conduction loss (W)

$P_{\text {con, } M} \quad$ MOSFET conduction loss (W)

$P_{\text {con,IGBT }} \quad$ IGBT conduction loss (W)

$P_{S W, I G B T} \quad$ IGBT switching loss (W)

$P_{S W, M} \quad$ MOSFET switching loss (W)

$Q_{c} \quad$ Schottky diode junction charge (C)

$R_{C} \quad$ Collector resistance $(\Omega)$

$R_{d c} \quad$ Inductor DC resistance $(\Omega)$

$R_{D S(o n)} \quad$ Drain to source on resistance $(\Omega)$

$T_{s w} \quad$ Switching period (s)

$v_{C E} \quad$ Instantaneous collector to emitter voltage (V)

$v_{C E O} \quad$ Collector to emitter voltage $(\mathrm{V})$

$v_{D S} \quad$ Instantaneous drain to source voltage $(\mathrm{V})$

$V_{D S} \quad$ Drain to source voltage in off condition (V) 
$V_{f D} \quad$ Diode on state voltage drop (V)

$V_{o} \quad$ Output DC voltage $(\mathrm{V})$

\section{Introduction}

At present, applications of power semiconductor devices based system such as converters, inverters etc. in any electric system is ubiquitous. Highly efficient power semiconductor devices have shown a great application in converters and have led to higher efficiency, low weight and compact size of system in last few decades. The silicon (Si) metal oxide semiconductor field effect transistor (MOSFET) are widely used for voltage up to $600 \mathrm{~V}$ [1]. Nonetheless, Si power devices applications is limited concerning the high efficiency, high power density, high voltage and high temperature applications due to the inherent material characteristics. Aforementioned drawbacks makes Si device less competitive for the higher power and efficient applications. For higher voltage application such as $600 \mathrm{~V}$ and above, insulated gate bipolar transistors (IGBTs) have shown useful applications but they become less efficient at high frequency due to high switching losses (because it is a minority carrier device). In evolution of more advanced power electronics devices, silicon carbide (SiC) MOSFET is more advantages in high power and voltage applications due to higher switching speed, high operating electric field, low on-state resistance and higher breakdown voltages [2-5]. Wide energy band gap and high thermal conductivity of $\mathrm{SiC}$ device enable them to operate at higher temperature and power. SiC devices are more efficient because of lower switching and conduction losses as compared to the Si and IGBT [6, 7]. Table 1 provides the comparative analysis of electrical and thermal properties of $\mathrm{Si}$ and $\mathrm{SiC}$ devices [8-11].

Several studies have been carried out for efficiency comparison of Si and SiC MOSFETs based DC-DC converter. Masich et al. have performed the efficiency comparison between the Si and SiC MOSFETs based DC-DC

Table 1 Electrical and thermal properties for Si, SiC MOSFET

\begin{tabular}{lll}
\hline Parameters & Si & $4 \mathrm{H}: \mathrm{SiC}$ \\
\hline Band gap $(\mathrm{eV})$ & 1.12 & 3.26 \\
Breakdown electric field $(\mathrm{MV} / \mathrm{cm})$ & 0.25 & 2.2 \\
Thermal conductivity $(\mathrm{W} / \mathrm{cm} \mathrm{K})$ & 1.5 & 3.7 \\
Electron mobility $\left(\mathrm{cm}^{2} / \mathrm{V} \mathrm{s}\right)$ & 1400 & 1000 \\
Hole mobility $\left(\mathrm{cm}^{2} / \mathrm{V} \mathrm{s}\right)$ & 450 & 140 \\
Intrinsic carrier concentration $\left(\right.$ per $\left.\mathrm{cm}^{3}\right)$ at & $1.5 \times 10^{10}$ & $5 \times 10^{-9}$ \\
$\quad 300 \mathrm{~K}$ & & \\
Electron saturation velocity $\left(\times 10^{7} \mathrm{~cm}^{-\mathrm{s}}\right)$ & 1 & 2 \\
Relative dielectric constant & 11.8 & 10 \\
\hline
\end{tabular}

SN Applied Sciences

a SPRINGER NATURE journal boost converter. A high voltage gain boost converter was designed for low power application $(\approx 20 \mathrm{~W})$ which is suitable for light emitting diode (LED). DC-DC converter efficiency was improved from 76 to $89 \%$ and 68 to $81 \%$ with variation in the switching frequency from the $120 \mathrm{kHz}$ to $20 \mathrm{kHz}$ at $600 \mathrm{~V}$ and $900 \mathrm{~V}$ output voltage, respectively [12]. Han et al. have performed the comparative study on the efficiency, weight and volume of $\mathrm{SiC}$ and Si based bidirectional DC-DC converter for the hybrid electrical vehicle. They studied the three configurations such as IGBT device with silicon diode, IGBT with SiC Schottky diode and SiC MOSFET with SiC Schottky diode. A comparative efficiency analysis was carried out at $20 \mathrm{kHz}$ switching frequency. The highest efficiency $\approx 99 \%$ was achieved with the use of SiC MOSFET with SiC Schottky diode at full load condition, whereas the efficiency for IGBT with SiC Schottky diode was $98.2 \%$. The efficiency for the IGBT and silicon PN diode configuration was found to be $97.6 \%$. There was significant reduction in weight of the converter from 8 to $3 \mathrm{~kg}$ with switching frequency of $20 \mathrm{kHz}$ to $200 \mathrm{kHz}$, respectively. It was also observed that only the $\mathrm{SiC}$ based converter have efficiency higher than $90 \%$ at $200 \mathrm{kHz}$ switching frequency [13]. Shi et al. have studied the SiC based on-board plug-in-electric vehicle (PEV) charger using single-ended primary-inductor converter (SEPIC) based power factor correction (PFC) converter followed by an isolated LLC resonant converter. It was found that the SEPIC-PFC converter achieved unity power factor, $2.72 \%$ total harmonic distortion, and $95.3 \%$ peak efficiency. The LLC converter achieved $97.1 \%$ peak efficiency. The overall efficiency of the PEV charger increased from 88.5 to $93.5 \%$ with increase in the load from $20 \%$ to full load [14]. Schrittwieser et al. [15] have done study on a three-phase buck PFC rectifier with integrated active filter for $380 \mathrm{~V} D C$ distribution systems that showed a peak efficiency $\approx 99 \%$ is achieved with $\mathrm{SiC}$ devices. Zhao et al. have performed comparative theoretical and experimental analysis for the isolated bidirectional DC-DC converter using $\mathrm{Si}$ and SiC devices. The $\mathrm{SiC}$ devices based converter showed the higher efficiency as compared to the Si based converter [16]. Rizzoli et al. have carried out a study on the performance evaluation of an inverter based on the soft and hard-switching $\mathrm{SiC}$ devices. It was found that hard-switching $\mathrm{SiC}$ inverter showed higher efficiency at lower output and also it was more economical as it eliminated the complex circuitry to drive the SiC MOSFET [17]. Anthon et al. have demonstrated the use of the $\mathrm{SiC}$ devices in multilevel grid-tied inverter. The use of the $\mathrm{SiC}$ devices reduced the semiconductor losses by more than $50 \%$ for similar rated capacity, load and frequency as compared to Si-IGBT device. In the application of the SiC device based inverter, the switching frequency was increased by 12 times while semiconductor losses were similar as in case of Si-IGBT inverter [18]. 
Ho et al. have done the performance comparison of interleaved boost converter based on the of $\mathrm{Si}$ and $\mathrm{SiC}$ diodes for photovoltaic applications. The use of $\mathrm{SiC}$ diode reduced the heat sink size (from 1031 to $388 \mathrm{~cm}^{3}$ ) and increased the converter efficiency by $0.6 \%$ [19]. In another study, Wang et al. have demonstrated the efficiency improvement in the $10 \mathrm{~kW}$ bidirectional electric vehicle charger using the variable DC bus voltage. It was found that efficiency increased by $0.7-1.25 \%$ using the variable DC bus voltage as compared to constant $600 \mathrm{~V}$ DC bus voltage [20]. Similar types of study for efficiency comparison of Si and SiC devices for DC-DC interleaved, bidirectional converter and inverter have been done [21-29]. The thermal performance of the converter using $\mathrm{Si}$ and SiC MOSFETs has been studied in order to estimate the junction temperature, heat losses and temperature distribution [21, 30-32].

In present study, a comparative analysis of efficiency and losses for DC-DC converter is performed for different devices applications such as $\mathrm{Si}, \mathrm{SiC}$ and IGBT. A $500 \mathrm{~W}$ power and $110 \mathrm{~V}$ output voltage DC-DC converter which have single gate driver circuit for all devices was developed in the laboratory. A theoretical prediction methodology is given which provides a details insight of conduction, switching losses for different devices along with inductor and capacitor losses. Three cases are studied to estimate the losses in the converter using theoretical prediction and experimental analysis such as (1) Si MOSFET + SiC diode, (2) $\mathrm{SiC}$ MOSFET + SiC diode, and (3) IGBT device + SiC diode.

Out of the three conventional DC/DC converter topologies i.e. buck, boost and buck-boost, boost topology is selected for the efficiency comparison. The reasons for choosing this topology are: (a) The input current of the boost converter is continuous which make it suitable to use with renewable power generators [33], (b) The gate driver circuit is not complex as it uses the low side driving circuitry. A single driver circuit is suitable to drive all types of power semiconductor devices namely $\mathrm{Si}, \mathrm{SiC}$ MOSFET and IGBT, (c) With change in the duty cycle there is approximately no change in the efficiency whereas for other topologies the efficiency changes significantly. This characteristics is utilized for further enhancement in the efficiency [34].

\section{Material and methodology}

\subsection{Gate driver circuit}

In this study for designing of boost converter, LM5022 controller is used as PWM generator whereas UCC27531 is used as the gate driver. Si MOSFET and IGBT require the $12 \mathrm{~V}$ (pk-pk) whereas SiC needs $18 \mathrm{~V}$ (pk-pk) as the driving voltage at the gate-source terminals. UCC27531 driver provides the necessary voltage to drive the $\mathrm{Si}, \mathrm{SiC}$ and IGBT in the boost converter. UCC27531 utilizes the output PWM signal $7 \mathrm{~V}$ (pk-pk) of LM5022 controller and generate the

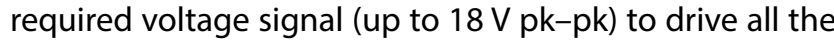
devices used. A feedback regulator power supply circuit is designed which supply the power to the LM5022 boost controller and UCC27531 gate-driver. Feedback regulator circuit provides the stable voltage $(12 \mathrm{~V} / 18 \mathrm{~V})$ irrespective of variation in the supply voltage $(30-72 \mathrm{~V})$. The schematic diagram of the feedback regulator circuit is shown in Fig. 1. In case of SiC MOSFET, higher gate-source voltage is required as compared to Si MOSFET because SiC carrier mobility and channel resistance are lower and higher, respectively in comparison with the Si. Higher the gate-source voltage lowers the drain-to-source resistance which gets saturated at a voltage of $18 \mathrm{~V}$. If $\mathrm{SiC}$ is driven by the gate-source voltage of $12 \mathrm{~V}$ then drain-source on-resistance is lower. In this case, there will be higher losses in the device that will increase the temperature of the device. Increase in the temperature will further increase the on-resistance due to the decrease in the carrier mobility of SiC. Therefore, $\mathrm{SiC}$ device can be damaged due to the thermal runway [35]. The circuit layout of the studied boost converter is shown in Fig. 2. The regulated output voltage from the feedback regulator circuit is supplied to the pin 1 of LM5022 and pin 6 of UCC27531 to bias these ICs. The generated PWM (7 V pk-pk) from controller LM5022 from pin 5 is given to the pin 2 of UCC27531. This PWM signal of $7 \mathrm{~V}$ (pk-pk) is amplified to the desired voltage level in the range $(12-18 \mathrm{~V})$ at the same voltage that is generated by the feedback regulator circuit.

\subsection{Converter losses theoretical calculation}

There are several losses occur in DC-DC boost converter such as MOSFET switching and conduction losses, diode conduction losses, inductor and capacitor losses. All of these losses can be calculated theoretically. The methodology used in calculation of different losses are given as following.

\subsubsection{MOSFET losses}

The losses in the MOSFET can be calculated as follows:

2.2.1.1 Conduction loss The conduction loss in the MOSFET is due to the drain-source on-resistance $\left(R_{D S(o n)}\right)$. The on-resistance varies with change in the drain current and junction temperature. The voltage drop can be expressed as below:

$v_{D S}\left(i_{d}, T\right)=i_{D} \cdot R_{D S(\text { on })}\left(i_{D}, T\right)$

Instantaneous value of the conduction loss can be formulated as follows: 
Fig. 1 Circuit to provide power to boost-controller LM5022 and gate-driver UCC27531

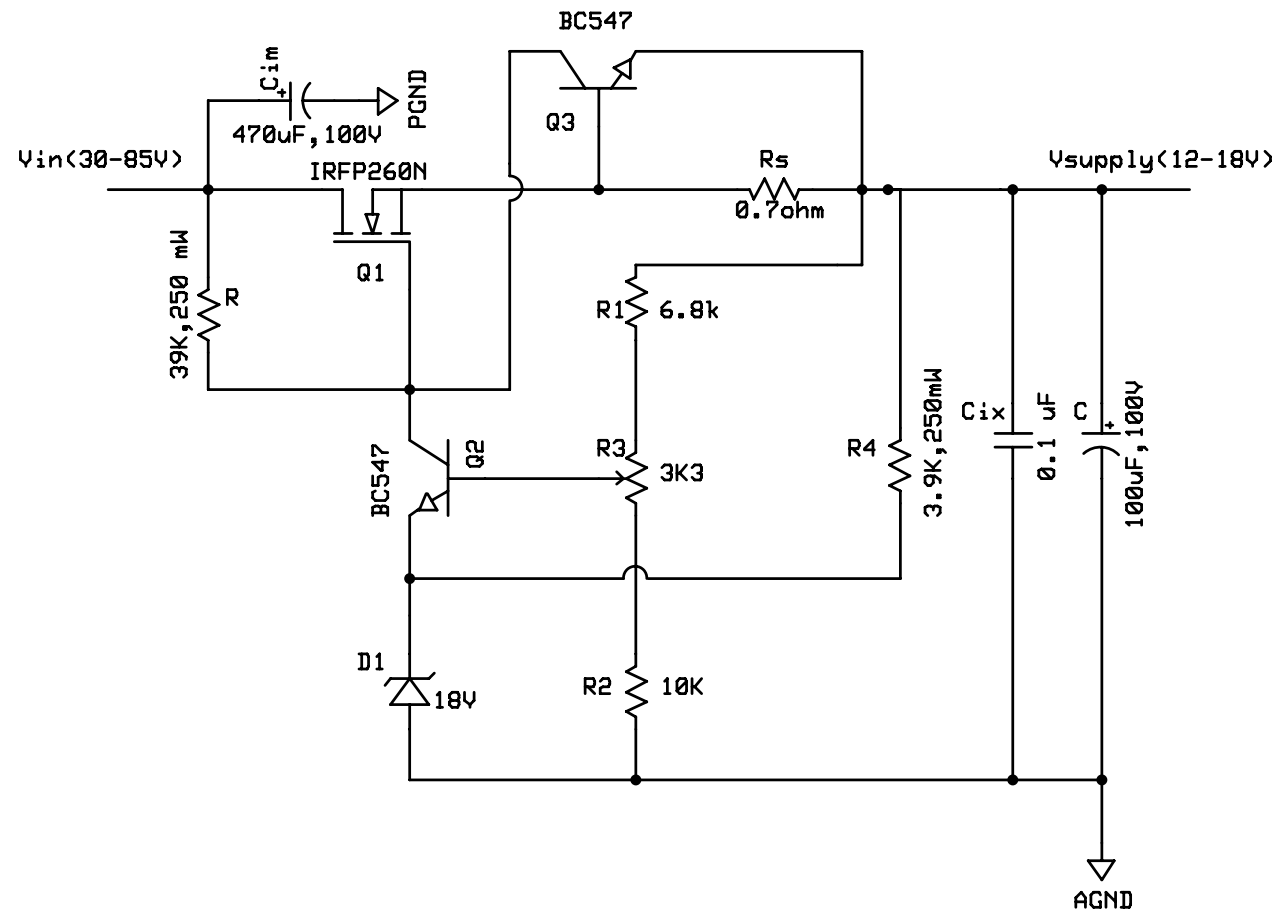

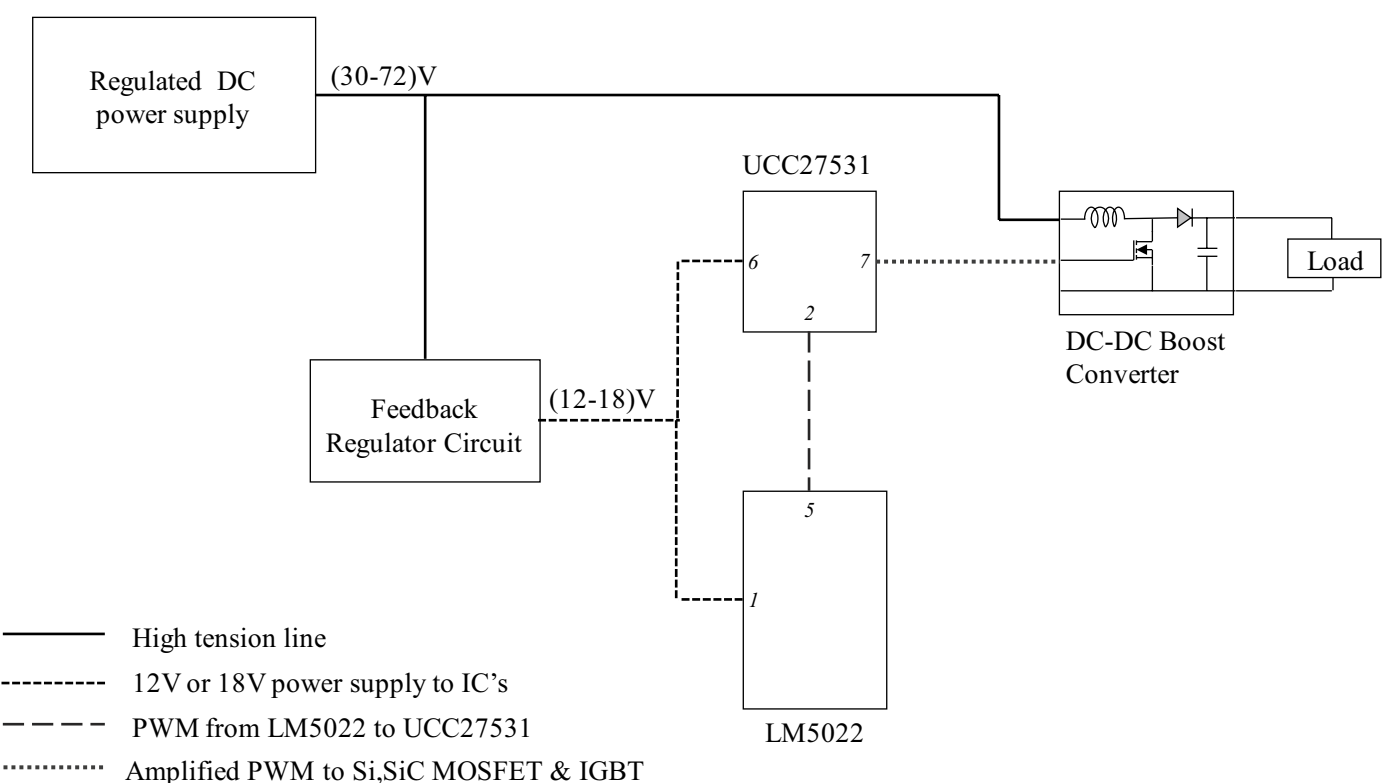

Fig. 2 Layout of boost converter with driver circuit

$P_{\text {con, } M}(t)=v_{D S}(t) \cdot i_{D}(t)=i_{D}(t)^{2} \cdot R_{D S(o n)}$

The average value of the conduction loss for switch-

$$
P_{\text {con, } M}=\frac{1}{T_{s w}} \int_{0}^{T_{s w}} P_{\text {con }, M}(t) d t=R_{D S(o n)} \cdot I_{D r m s}^{2}
$$
ing period can be expressed as below:

\section{SN Applied Sciences}


2.2.1.2 Switching loss Switching loss of MOSFET majorly depends on the ON and OFF states energy losses of MOSFET. The MOSFET switching loss is calculated with considering the loss associated with ON and OFF states of the MOSFET. The ON-state energy loss is calculated without considering the loss associated with reverse recovery process of MOSFET. However, loss associated with the reverse recovery process with anti-parallel diode is considered for calculating the $\mathrm{ON}$-state loss.

The switching loss of MOSFET is given by:

$P_{s w, M}=\left(E_{o n, M}+E_{o f f, M}\right) f_{s w}$

The values of parameters used in theoretical calculation of conduction and switching losses are taken from the MOSFET datasheets [36, 37].

\subsubsection{IGBT losses}

The IGBT conduction and switching losses are calculated in similar way as the conduction and switching losses are calculated for the MOSFET. The drain, source and gate for MOSFET are similar to the collector, emitter and base of IGBT, respectively. The conduction loss in IGBT is given by:

2.2.2.1 IGBT conduction loss The instantaneous value of the conduction loss associated with IGBT is given by:

$P_{\text {COn,IGBT }}(t)=v_{C E}(t) \cdot i_{C}(t)=\left(v_{C E O}+R_{c} i_{c}(t)\right) i_{c}(t)=v_{C E O} i_{c}(t)+R_{c} i_{c}(t)^{2}$

The average value of the IGBT conduction loss is represented as follows:

$$
\begin{aligned}
P_{\text {COn,IGBT }}= & \frac{1}{T_{S w}} \int_{0}^{T_{s w}} v_{C E}(t) \cdot i_{c}(t) d t=\frac{1}{T_{s w}} \int_{0}^{T_{s w}}\left(v_{C E O}+R_{c} i_{C}\right) \cdot i_{c}(t) d t \\
& =v_{C E O} \cdot l_{C a v}+R_{C} \cdot l_{C r m s}^{2}
\end{aligned}
$$

2.2.2.2 IGBT switching loss IGBT switching loss is given by:

$$
P_{S W, I G B T}=\left(E_{o n, I G B T}+E_{o f f, I G B T}\right) \cdot f_{s W}
$$

The values of parameters used in theoretical calculation of conduction and switching losses are taken from the IGBT datasheet [38].

\subsubsection{Diode losses}

The boost converter diode also has two types of losses such as conduction and switching losses. These losses can be explained as below:

2.2.3.1 Diode conduction loss Conduction loss in diode can be formulated as below:

$P_{\text {con,D }}=V_{f D} I_{o}$

2.2.3.2 Diode switching loss Switching loss in diode can be expressed as below:

$P_{s w, D}=Q_{c} \cdot V_{o} \cdot f_{s w}$

The values of parameters used in theoretical calculation of conduction and switching losses are taken from the Schottky diode datasheet [39].

\subsubsection{Inductor and capacitor losses}

In the inductor, there are major losses such as conduction or copper losses. These losses can be expressed as below:

$P_{L}=l_{L r m s}^{2} \cdot R_{d c}$

where, $\quad I_{\text {Lrms }}^{2}=l_{o}^{2}+\frac{\Delta l^{2}}{12}$

and $\Delta l$ is the ripple current which is approximately $30 \%$ of the output current and $\Delta I^{2}$ can be neglected. Therefore, the inductor conduction loss can be simplified as below:

$P_{L}=l_{o}^{2} \cdot R_{d c}$

In the capacitor the losses can be expressed as:

$P_{c}=l_{c}^{2} \cdot E S R$

\subsection{Experimental setup}

An experimental study is performed with the DC-DC boost converter $(110 \mathrm{~V}, 500 \mathrm{~W})$ for the comparative efficiency analysis using $\mathrm{Si}$, SiC MOSFET and IGBT. The details of the power semiconductor devices such as $\mathrm{Si}$, SiC MOSFETs, IGBT and diodes are given in Table 2. The designed prototype of the boost converter is shown in Fig. 3 and the power semiconductor devices (Si and SiC MOSEFT, IGBT and SiC diode) used in the study is shown in Fig. 4. 
Table 2 Details of devices used in experimental study

\begin{tabular}{llllll}
\hline Device & Manufacturer & Model number & $\begin{array}{l}\text { Reverse voltage } \\
\text { rating }(\mathrm{V})\end{array}$ & $\begin{array}{l}\text { Forward current rat- } \\
\text { ing @ 25 }{ }^{\circ} \mathrm{C}(\mathrm{A})\end{array}$ & $\begin{array}{l}\text { Drain-to-source } \\
\text { on resistance } \\
(\mathrm{m} \Omega)\end{array}$ \\
\hline Si MOSFET & ST Microelectronics & STW65N65DM2AG & 650 & 60 & 50 \\
SiC MOSFET & ROHM Semiconductor & SCT3030AL & 650 & 70 & 30 \\
IGBT & International rectifier & IRGP4262DPBF & 650 & 60 & - \\
Schottky diode & CREE & CVFD20065A & 650 & 57 & - \\
\hline
\end{tabular}

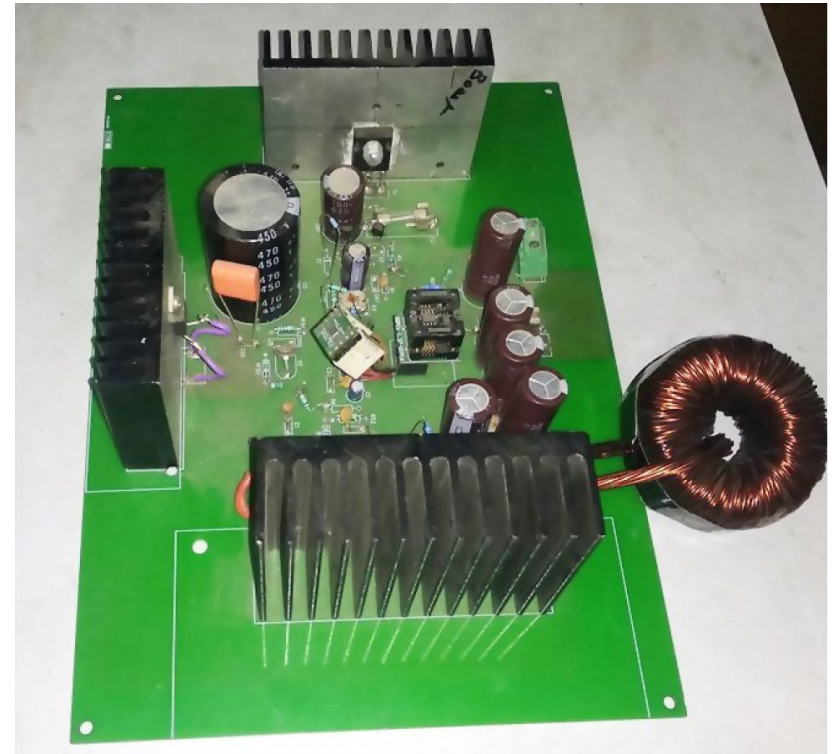

Fig. 3 Prototype of dc-dc converter

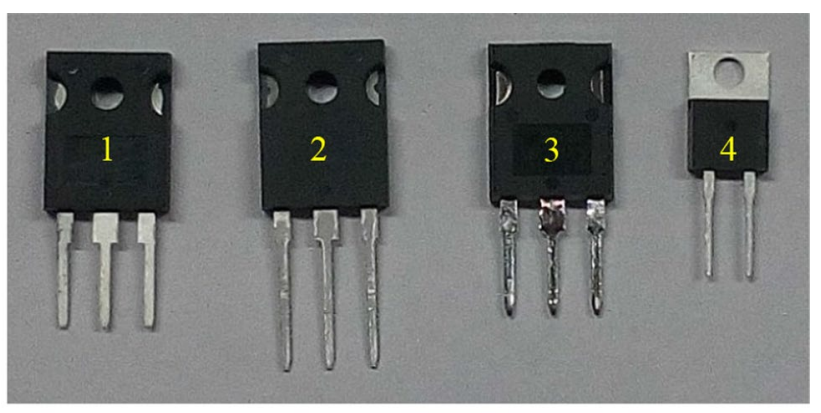
1- Si MOSFET
3- IGBT
4- SiC Schottky diode

Fig. 4 Power semiconductor devices used in the study

\section{Results and discussion}

\subsection{Theoretical prediction of losses in DC-DC converter}

The theoretical prediction of different losses in DC-DC converter is shown in Figs. 5, 6, 7 and 8 for different switching

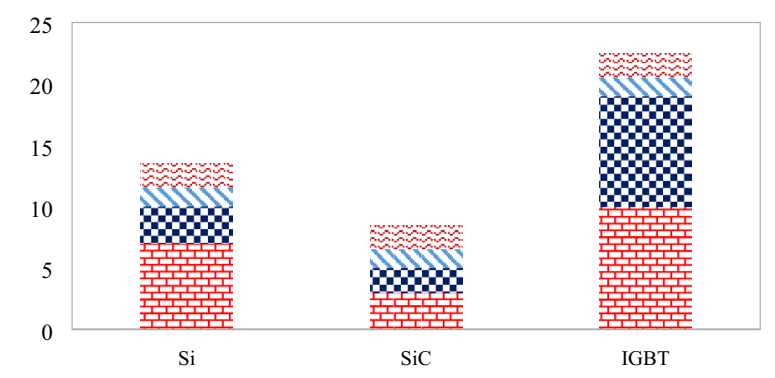

ᄃ Conduction Loss $\square$ Switching Loss

Fig. 5 Losses in DC-DC converter at $20 \mathrm{kHz}$ for $250 \mathrm{~W}$

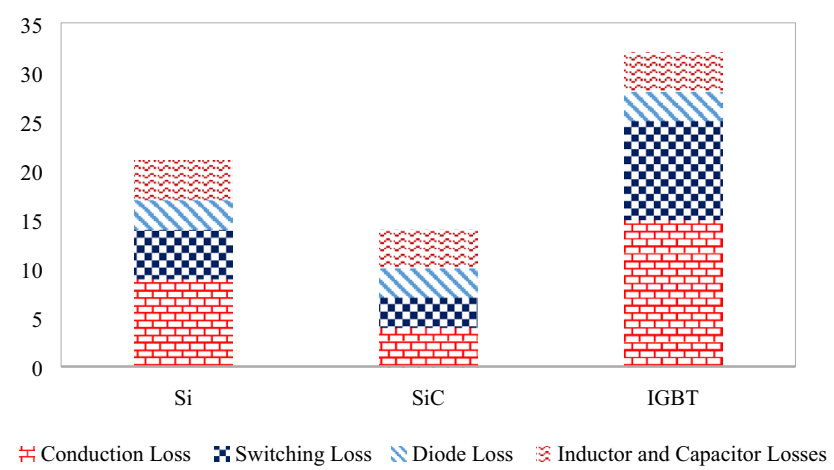

Fig. 6 Losses in DC-DC converter at $20 \mathrm{kHz}$ for $500 \mathrm{~W}$

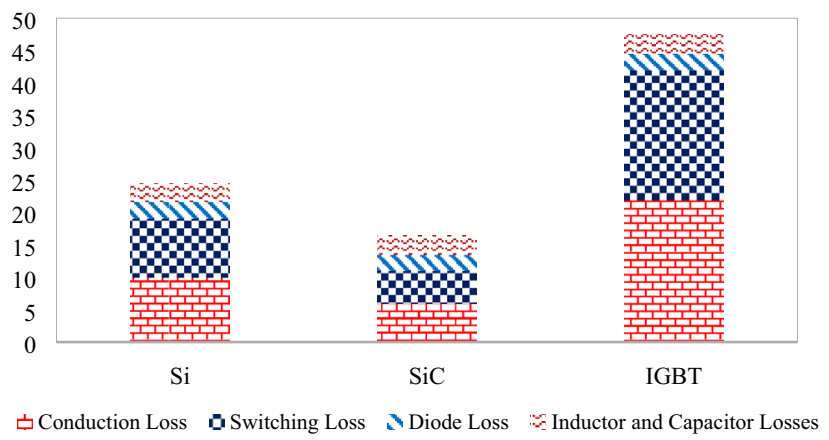

Fig. 7 Losses in DC-DC converter at $50 \mathrm{kHz}$ for $250 \mathrm{~W}$ 


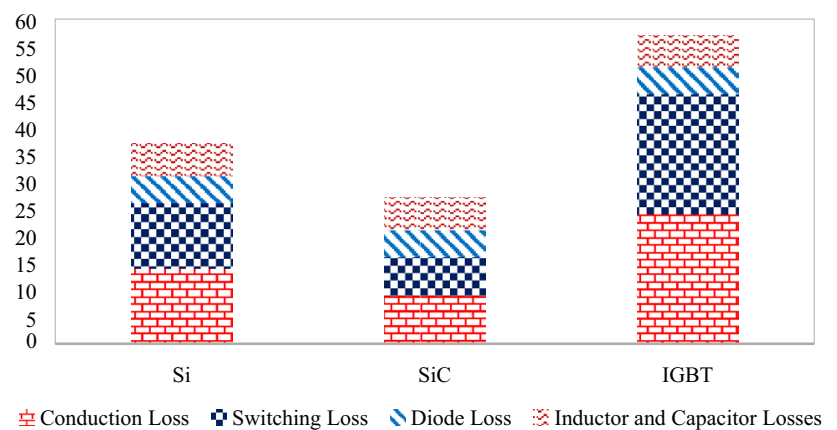

Fig. 8 Losses in DC-DC converter at $50 \mathrm{kHz}$ for $500 \mathrm{~W}$

frquencies and power. These losses are calculated uisng the Eqs. (1)-(13).

Figures 5 and 6 show the comparison between different losses for $250 \mathrm{~W}$ and $500 \mathrm{~W}$ power output, respectively at $20 \mathrm{kHz}$ switching frequency. It was found that at $20 \mathrm{kHz}$ frequency and $250 \mathrm{~W}$ power output, IGBT incurs maximum conduction loss $\approx 10 \mathrm{~W}$ followed by the $\mathrm{Si}(7 \mathrm{~W})$ and $\mathrm{SiC}$ (3 W). In comparison of switching loss for $250 \mathrm{~W}$ power output, IGBT has maximum $\approx 9 \mathrm{~W}$ followed by $\mathrm{Si} \approx 3 \mathrm{~W}$ and $\mathrm{SiC} \approx 2 \mathrm{~W}$. Diode loss $(1.5 \mathrm{~W})$ is similar for all IGBT, Si and SiC applications in the converter. Inductor losses are found to be $\approx 2 \mathrm{~W}$ at $20 \mathrm{kHz}$ switching frequency. The similar pattern for losses is followed for the $500 \mathrm{~W}$ load power at $20 \mathrm{kHz}$ switching frequency.

However, at $50 \mathrm{kHz}$ switching frequency, total losses increases for all the devices. As shown in Fig. 7 at $50 \mathrm{kHz}$ switching frequency and $250 \mathrm{~W}$ load, power conduction and switching losses increase for all devices as compared to $20 \mathrm{kHz}$ frequency, however it is still higher for the IGBT followed by the Si and SiC. Similar pattern is followed for $500 \mathrm{~W}$ power at $50 \mathrm{kHz}$ frequency as shown in Fig. 8. Inductor loss also increases as the switching frequency increases. However, inductor and capacitor losses increase as load power increases from 250 to $500 \mathrm{~W}$ at $50 \mathrm{kHz}$ frequency.

Conduction loss majorly depends on the load current, junction temperature, duty cycle while switching loss is function of switching speed, load voltage, load current and junction temperature. The conduction loss in the SiC is less than its counterparts because the on-state resistance is low. The resistance of $\mathrm{SiC}$ device is dependent on the applied voltage, its off-state resistance is high. SiC onstate resistance decreases significantly until a threshold voltage is applied to it and maintains this resistance until applied voltage is below threshold voltage. The on-state resistance is majorly depends on the thickness of drift layer. In SiC, the thickness of drift layer is reduced 10 times as compared to $\mathrm{Si}$ while the concentration of doping is kept in magnitude of same order in case of Si. Therefore, the $\mathrm{SiC}$ offers almost 10 times lesser on-state resistance as compared to Si. In contrast of SiC, Si MOSFET on-state resistance increases with increase in the gate-source voltage. The increment in the on-state resistance of Si MOSFET is proportional to square of voltage to gate to source voltage. The switching losses in IGBT are higher than the SiC MOSFET, because due to inherent bipolar characteristic of IGBT. Being as bipolar device the conduction in the IGBT happens due to both electrons and holes. Therefore, during the transition from on-state to off-state, there are some electrons and holes are trapped in the channel. Therefore, IGBT will not be fully turned off until all electrons and holes are recombined. During this transition time, miller capacitance holds some gate voltage, therefore some losses happens during this period. $\mathrm{SiC}$ device has unipolar conduction which happens due to electrons flow only. During the transition from the on state to off state, only electrons flow is inhibited by closing the channel. Therefore, there is no delay in the turning off completely in the SiC MOSFET.

\subsection{Experimental efficiency analysis of the converter}

This section explains the experimental analysis of efficiency in the DC-DC converter.

The efficiency comparison of $\mathrm{Si}$, SiC MOSFETs and IGBT device based DC-DC boost converter for three different input voltages $30 \mathrm{~V}, 50 \mathrm{~V}$ and $72 \mathrm{~V}$ is shown in Figs. $9 \mathrm{a}, \mathrm{b}$, $10 a, b$, and $11 a, b$, respectively. In Fig. 9a, efficiency comparison is shown for $20 \mathrm{kHz}$ switching frequency at $30 \mathrm{~V}$ input voltage. The converter efficiency increases with increase in the output power. The efficiency is highest for SiC MOSFET based converter and was found to be $95.8 \%$. The efficiency for Si MOSFET and IGBT are found to be $94.6 \%$ and $92.6 \%$, respectively. In Fig. 9b, the converter efficiency comparison is done for $50 \mathrm{kHz}$ switching frequency at the $30 \mathrm{~V}$ input voltage. The highest efficiency is $93.4 \%$ for $\mathrm{SiC}$ based converter, whereas the efficiency is lower for Si MOSFET and IGBT which are found to be $91.8 \%$ and $88.4 \%$, respectively. In Fig. $10 a$, b, the efficiency comparison is done for $50 \mathrm{~V}$ input voltage at $20 \mathrm{kHz}$ and $50 \mathrm{kHz}$ switching frequency. It is shown in Fig. 10a that the efficiency is higher for SiC MOSFET and it is found to be $96.7 \%$, whereas the lowest efficiency is for IGBT and it is found to be $93.8 \%$. From Fig. 10b, it is clear that efficiency decreases with increase in the frequency for all the devices. The efficiency for SiC MOSFET decreases to $94.7 \%$ from $96.7 \%$, whereas the efficiency for IGBT decreases to $89.6 \%$ from 93.8\%. In Fig. 11 a, b the efficiency comparison is done for $72 \mathrm{~V}$ input voltage at two different switching frequencies of $20 \mathrm{kHz}$ and $50 \mathrm{kHz}$. From Fig. 11, it is clear that the efficiency is still highest $97.8 \%$ in case of $\mathrm{SiC}$, whereas the lowest efficiency is found for IGBT which is $93.9 \%$.The efficiency for $\mathrm{SiC}$ decreases to $95.8 \%$ (at $50 \mathrm{kHz}$ ) from $97.85 \%$ 


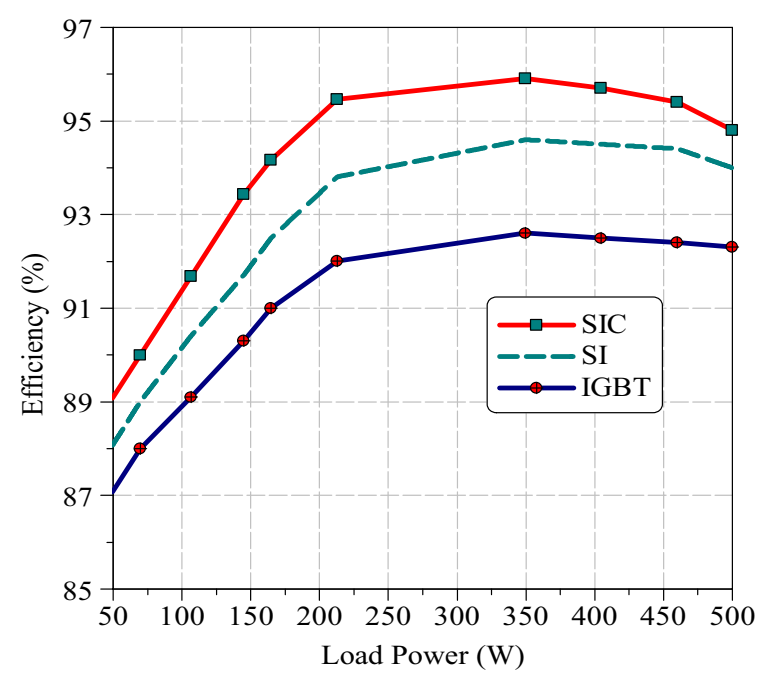

(a)

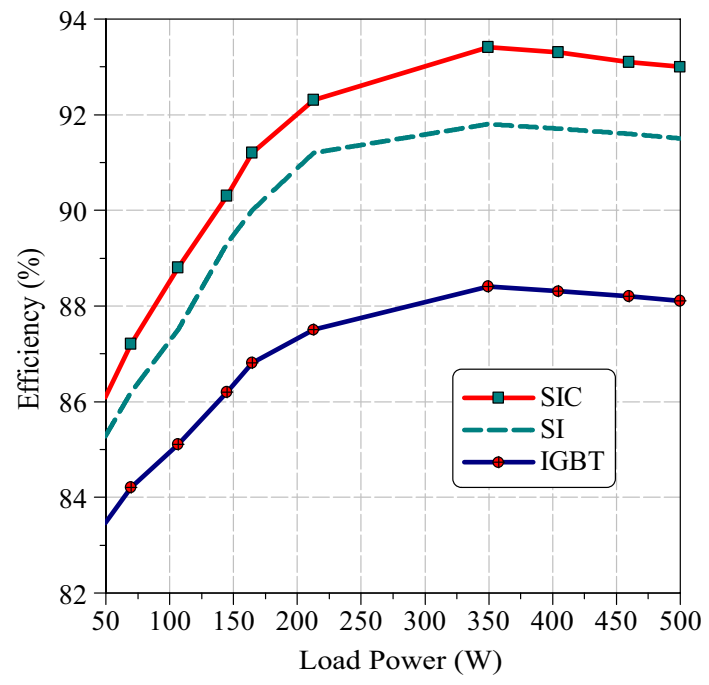

(b)

Fig. 9 Efficiency comparison for $30 \mathrm{~V}$ input at a $20 \mathrm{kHz}, \mathbf{b} 50 \mathrm{kHz}$ switching frequency

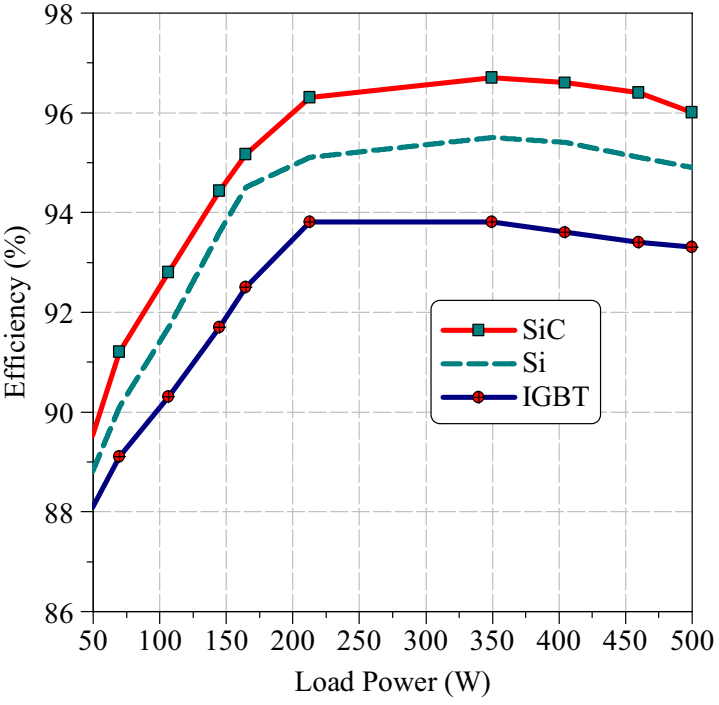

(a)

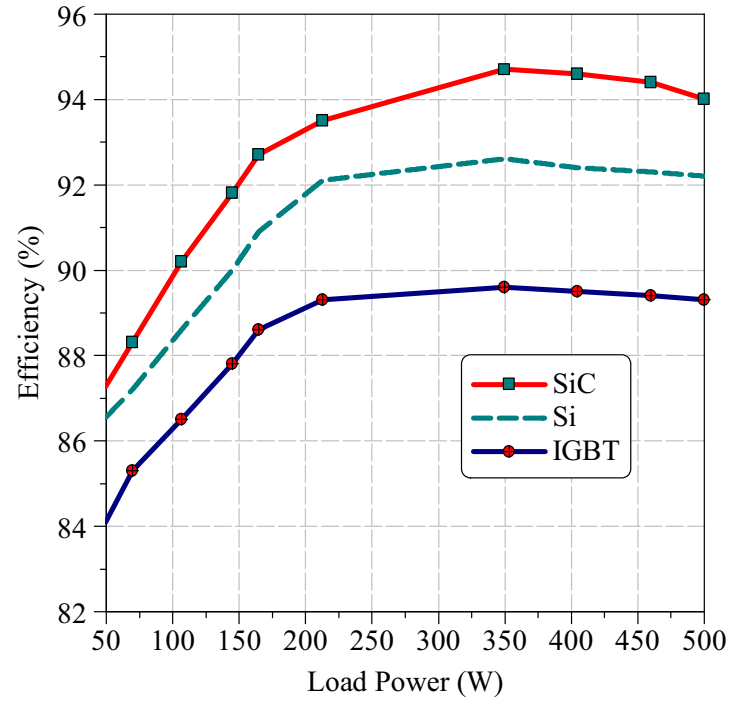

(b)

Fig. 10 Efficiency comparison for $50 \mathrm{~V}$ input at a $20 \mathrm{kHz}$, b $50 \mathrm{kHz}$ switching frequency

(at $20 \mathrm{kHz}$ ) and for IGBT the efficiency decreases to $89.7 \%$ (at $50 \mathrm{kHz}$ from $93.4 \%$ (at $20 \mathrm{kHz}$ ). The application of SiC converter improves the efficiency of converter significantly due to lower conduction losses (lower on-resistance and low parasitic capacitance) as compared to Si and IGBT. Besides this, SiC has faster ON and OFF transitions, therefore it has lower switching losses.

The converter efficiency increases with increase in the load power (as power output increases while switching loss does not vary much). Nonetheless, efficiency further decreases with increase in the output power (further increase in the load power, conduction loss dominates more). Therefore, efficiency comes lower for further increase in the load power.

\subsection{Comparison between experimental and theoretical predicted efficiencies}

At $50 \%$ of the total load, the calculated and measuered efficiency differences at $20 \mathrm{kHz}$ and $50 \mathrm{kHz}$ are given in Tables 3 and 4, respectively. 


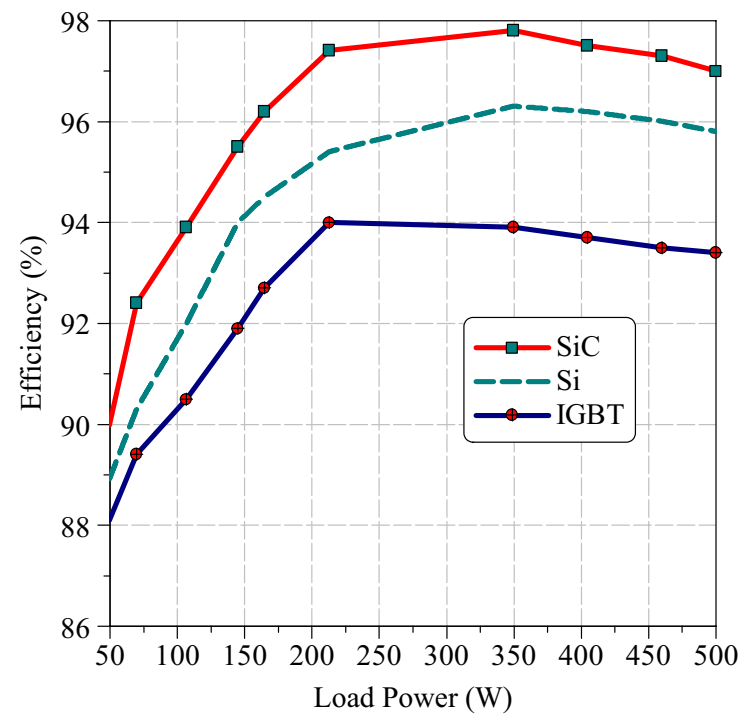

(a)

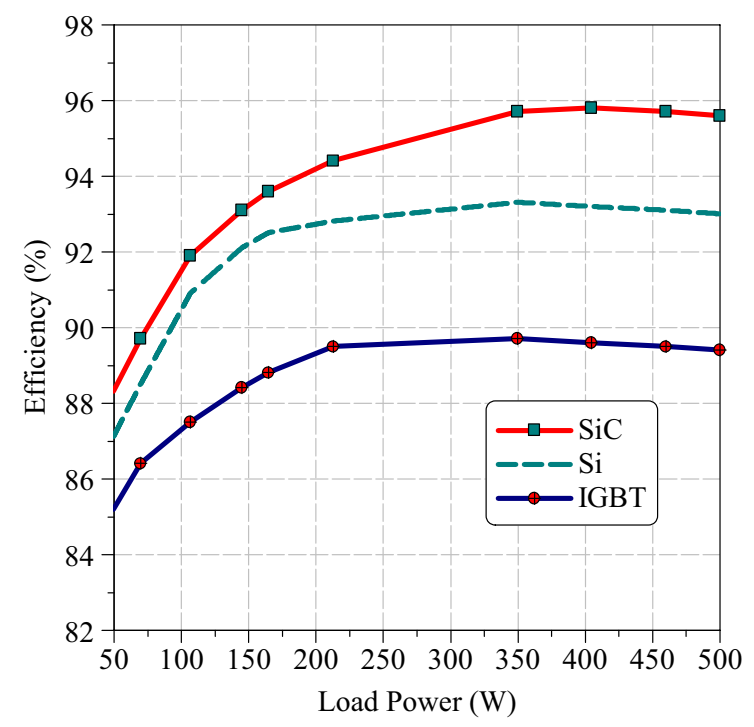

(b)

Fig. 11 Efficiency comparison for $72 \mathrm{~V}$ input at a $20 \mathrm{kHz}$, b $50 \mathrm{kHz}$ switching frequency

Table 3 Measured and calculated efficiency differences for $250 \mathrm{~W}$ load at $20 \mathrm{kHz}$

\begin{tabular}{llll}
\hline Device & $\begin{array}{l}\text { Calculated effi- } \\
\text { ciency (\%) }\end{array}$ & $\begin{array}{l}\text { Measured effi- } \\
\text { ciency (\%) }\end{array}$ & Difference (\%) \\
\hline $\mathrm{Si}$ & 97.37 & 95.4 & 1.97 \\
$\mathrm{SiC}$ & 98.30 & 97.4 & 0.9 \\
IGBT & 95.70 & 94.0 & 1.7 \\
\hline
\end{tabular}

Table 4 Measured and calculated efficiency difference for $250 \mathrm{~W}$ load at $50 \mathrm{kHz}$

\begin{tabular}{llll}
\hline Device & $\begin{array}{l}\text { Calculated effi- } \\
\text { ciency (\%) }\end{array}$ & $\begin{array}{l}\text { Measured effi- } \\
\text { ciency (\%) }\end{array}$ & Difference (\%) \\
\hline $\mathrm{Si}$ & 95.32 & 93.0 & 2.32 \\
$\mathrm{SiC}$ & 97.18 & 95.6 & 1.58 \\
$\mathrm{IGBT}$ & 92.33 & 89.4 & 2.93 \\
\hline
\end{tabular}

Table 5 Measured and calculated efficiency difference for $500 \mathrm{~W}$ rating at $20 \mathrm{kHz}$

\begin{tabular}{llll}
\hline Device & $\begin{array}{l}\text { Calculated effi- } \\
\text { ciency (\%) }\end{array}$ & $\begin{array}{l}\text { Measured effi- } \\
\text { ciency (\%) }\end{array}$ & Difference (\%) \\
\hline Si & 96.0 & 95.8 & 0.2 \\
SiC & 97.3 & 97.0 & 0.3 \\
IGBT & 93.8 & 93.4 & 0.4 \\
\hline
\end{tabular}

Calculated and measuered efficency differences for full load condition at $20 \mathrm{kHz}$ and $50 \mathrm{kHz}$ are given in Tables 5 and 6 respectively.
Table 6 Measured and calculated efficiency difference for $500 \mathrm{~W}$ rating at $50 \mathrm{kHz}$

\begin{tabular}{llll}
\hline Device & $\begin{array}{l}\text { Calculated effi- } \\
\text { ciency (\%) }\end{array}$ & $\begin{array}{l}\text { Measured effi- } \\
\text { ciency (\%) }\end{array}$ & Difference (\%) \\
\hline Si & 93.30 & 92.8 & 0.50 \\
SiC & 95.23 & 94.4 & 0.83 \\
IGBT & 90.25 & 89.5 & 0.75 \\
\hline
\end{tabular}

The theoretical prediction is also given for the conduction and switching losses in power transistor devices and inductor and capacitor losses. Tables 3 and 4 give the difference in the measured and theoretical efficiencies for $250 \mathrm{~W}$ power at $20 \mathrm{kHz}$ and $50 \mathrm{kHz}$ switching frequency, respectively. Tables 5 and 6 provide the difference in theoretical and measured values of efficiency for $500 \mathrm{~W}$ at $20 \mathrm{kHz}$ and $50 \mathrm{kHz}$ switching frequency, respectively. There is slight difference between the theoretical and experimentally measured values. There is reason which can causes the difference between the theoretical and measured values such as (1) Leakage losses in the parasitic resistance, capacitance and inductor in the converter circuit layout which are not considered in the theoretical prediction, (2) Parameter values for different devices $\mathrm{Si}$, $\mathrm{SiC}$ and IGBT in theoretical prediction are taken from the respective datasheet provided by the manufacturer which were obtained at the standard test condition and may be different in actual working condition, (3) Variable nature of switching frequency which is sensitive to unincorporated parasitic elements in the theoretical prediction. 


\section{Conclusions}

In this study, the comparison in the efficiency of the DC-DC boost converter using the Si and SiC MOSFETs and IGBT device has been studied on the basis of theoretical predictions and experimental analysis. Three cases such as (1) Si MOSFET + SiC diode, (2) SiC MOSFET + SiC diode, and (3) Si IGBT + SiC diode are compared to evaluate the comparative efficiency and losses for given power output at different operating frequency such as $20 \mathrm{kHz}$ and $50 \mathrm{kHz}$. It was found that at lower frequency $(20 \mathrm{kHz})$, the efficiency of DC-DC converter is maximum $97.8 \%$ and followed by Si and IGBT. However, the converter efficiency drops for all three aforementioned cases with increase in the switching frequency. The SiC MOSFET + SiC diode based converter gives maximum efficiency because of low conduction and switching losses. Conduction loss in $\mathrm{SiC}$ is lowest due to lower on-state resistance as compared to $\mathrm{Si}$ MOSFET and IGBT. Switching loss is also lowest in case of SiC MOSFET + SiC diode application due to the low miller capacitance (parasitic capacitance). The details comparative analysis of conduction, switching loss, inductor loss and capacitor loss are also given for $\mathrm{Si}$, SiC and IGBT devices in the converter. Conduction loss is maximum for IGBT followed by the Si and SiC. It is concluded that the application of the combination of power semiconductor devices (SiC MOSFET + SiC Schottky diode) in DC-DC converter provides the highest efficiency as compared to $\mathrm{Si}$ and IGBT devices.

\section{Compliance with ethical standards}

Conflict of interest On behalf of all authors, the corresponding author states that there is no conflict of interest.

\section{References}

1. Carr JA, Hotz D, Balda JC, Mantooth HA, Ong A, Agarwal A (2009) Assessing the impact of SiC MOSFETs on converter interfaces for distributed energy resources. IEEE Trans Power Electron 24:260-270

2. Cooper JA, Agarwal A (2002) SiC power-switching devices-the second electronics revolution. Proc IEEE 90:956-968

3. Singh R, Cooper JA, Melloch MR, Chow TP, Palmour JW (2002) $\mathrm{SiC}$ power Schottky and PiN diodes. IEEE Trans Electron Devices 49:665-672

4. Rabkowski J, Peftitsis D, Nee HP (2012) Silicon carbide power transistors-a new era in power electronics is initiated. IEEE Ind Electron Mag 6:17-26

5. Millan J, Godignon P, Perpina X, Pereztomas A, Rebollo J (2014) A survey of wide bandgap power semiconductor devices. IEEE Trans Power Electron 29:2155-2163
6. Zhao T, Wang J, Huang AQ, Agarwal A (2007) Comparisons of SiC MOSFET and Si IGBT based motor drive systems. In: Proceedings on IEEE industry applications conference, pp 331-335

7. Biela J, Schweizer M, Wafer S, Kolar JW (2011) SiC versus Si evaluation of potentials for performance improvement of inverter and DC-DC converter systems by $\mathrm{SiC}$ power semiconductors. IEEE Trans Ind Electron 58:2872-2882

8. Bhatnagar M, Baliga BJ (1993) Comparison of $6 \mathrm{H}-\mathrm{SiC}, 3 \mathrm{C}-\mathrm{SiC}$, and Si for power devices. IEEE Trans. Electron Devices 40:645-655

9. Elasser A, Chow TP (2002) Silicon carbide benefits and advantages for power electronics circuits and systems. Proc IEEE 90:969-986

10. Hudgins JL, Simin GS, Santi E, Khan MA (2003) An assessment of wide bandgap semiconductors for power devices. IEEE Trans Power Electron 18:907-914

11. Rujas A, López VM, Bediaga AG, Berasategi A, Nieva T (2017) Influence of SiC technology in a railway traction DC-DC converter design evolution. In: IEEE Energy conversion congress and exposition (ECCE), Cincinnati, OH, pp 931-938

12. Masich AL, Blavi HV, Moncusí JMB, Salamero LM (2015) Efficiency comparison between $\mathrm{Si}$ and SiC-based implementations in a high gain DC-DC boost converter. IET Power Electron 8:869-878

13. Han D, Noppakunkajorn J, Sarlioglu B (2014) Comprehensive efficiency, weight, and volume comparison of $\mathrm{SiC}$ - and Si-based bidirectional DC-DC converters for hybrid electric vehicles. IEEE Trans Veh Technol 63:3001-3010

14. Shi C, Wang H, Dusmez S, Khaligh A (2017) A SiC-based highefficiency isolated onboard PEV charger with ultrawide DC-link voltage range. IEEE Trans Ind Appl 53:501-511

15. Schrittwieser L, Kolar JW, Soeiro TB (2017) $99 \%$ efficient threephase buck-type SiC MOSFET PFC rectifier minimizing life cycle cost in DC data centers. CPSS Trans Power Electron Appl 2:47-58

16. Zhao B, Song Q, Liu W (2014) Experimental comparison of isolated bidirectional DC-DC converters based on all-Si and all-SiC power devices for next-generation power conversion application. IEEE Trans Ind Electron 61:1389-1393

17. Rizzoli G, Mengoni M, Zarri L, Tani A, Serra G, Casadei D (2019) Comparative experimental evaluation of zero-voltage-switching Si inverters and hard-switching $\mathrm{Si}$ and $\mathrm{SiC}$ inverters. IEEE J Emerg Sel Top Power Electron 7:515-527

18. Anthon A, Zhang Z, Andersen MAE, Holmes DG, McGrath B, Teixeira CA (2017) The benefits of SiC mosfets in a T-Type inverter for grid-tie applications. IEEE Trans Power Electron 32:2808-2821

19. Ho CNM, Breuninger H, Pettersson S, Escobar G, Canales F (2013) A comparative performance study of an interleaved boost converter using commercial Si and SiC diodes for PV applications. IEEE Trans Power Electron 28:289-299

20. Wang $X$, Jiang C, Lei B, Teng H, Bai HK, Kirtley JL (2016) Powerloss analysis and efficiency maximization of a silicon-carbide MOSFET-based three-Phase 10-kW bidirectional EV charger using variable-DC-bus control. IEEE J Emerg Sel Top Power Electron 4:880-892

21. Cougo B, Schneider H, Meynard T (2015) High current ripple for power density and efficiency improvement in wide bandgap transistor-based buck converters. IEEE Trans Power Electron 30:4489-4504

22. Zdanowski M, Kostov K, Rabkowski J, Barlik R, Nee HP (2014) Design and evaluation of reduced self-capacitance inductor in DC/DC converters with fast-switching SiC transistors. IEEE Trans Power Electron 29:2492-2499

23. Biela J, Schweizer M, Waffler S, Kolar JW (2011) SiC versus Sievaluation of potentials for performance improvement of inverter and DC-DC converter systems by SiC power semiconductors. IEEE Trans Ind Electron 58:2872-2882 
24. Hazra S, Madhusoodhanan S, Moghaddam GK, Hatua K, Bhattacharya $S$ (2016) Design considerations and performance evaluation of 1200-V 100-A SiC MOSFET-based two-level voltage source converter. IEEE Trans Ind Appl 52:4257-4268

25. Xu F, Guo B, Tolbert LM, Wang F, Blalock BJ (2013) An all-SiC three-phase buck rectifier for high-efficiency data center power supplies. IEEE Trans Ind Appl 49:2662-2673

26. Kasper M, Bortis D, Kolar JW (2014) Classification and comparative evaluation of PV panel-integrated DC-DC converter concepts. IEEE Trans Power Electron 29:2511-2526

27. Alfotouh AMA, Radun AV, Chang HR, Winterhalter C (2006) A 1-MHz hard-switched silicon carbide DC-DC converter. IEEE Trans Power Electron 21:880-889

28. Vechalapu K, Bhattacharya S, Brunt EV, Ryu SH, Grider D, Palmour JW (2017) Comparative evaluation of 15-kV SiC MOSFET and 15-kV SiC IGBT for medium-voltage converter under the same dv/dt conditions. IEEE J Emerg Sel Top Power Electron 5:469-489

29. Wang YF, Xue LK, Wang CS, Wang P, Li W (2016) Interleaved highconversion-ratio bidirectional DC-DC converter for distributed energy-storage systems-circuit generation, analysis, and design. IEEE Trans Power Electron 31:5547-5561

30. Hazra S, De A, Cheng L, Palmour J, Schupbach M, Hull BA, Allen S, Bhattacharya S (2016) High switching performance of 1700-V, 50-A SiC power MOSFET over Si IGBT/BiMOSFET for advanced power conversion applications. IEEE Trans Power Electron 31:4742-4754

31. Kim $T$, Jang $M$, Agelidis VG (2015) Practical implementation of a silicon carbide-based $300 \mathrm{kHz}, 1.2 \mathrm{~kW}$ hard-switching boost-converter and comparative thermal performance evaluation. IET Power Electron 8:333-341

32. Jiang D, Burgos R, Wang F, Boroyevich D (2012) Temperature-dependent characteristics of SiC devices: performance evaluation and loss calculation. IEEE Trans Power Electron 27:1013-1024

33. Graditi G, Colonnese D, Femia N (2010) Efficiency and reliability comparison of DC-DC converters for single phase grid connected photovoltaic inverters. In: SPEEDAM Pisa, pp 140-147

34. Glasner I, Appelbaum J (1996) Advantage of boost vs. buck topology for maximum power point tracker in photovoltaic systems. In: Proceedings of 19th convention of electrical and electronics engineers Jerusalem, Israel, pp 355-358

35. Zhou W, Zhong X, Sheng K (2014) High temperature stability and the performance degradation of SiC MOSFETs. IEEE Trans Power Electron 29:2329-2337

36. https://www.st.com/resource/en/datasheet/stw65n65dm2ag. pdf

37. https://www.rohm.com/datasheet/SCT3030AL

38. https://www.infineon.com/dgdl/irgp4262dpbf.pdf

39. https://www.wolfspeed.com/cvfd20065a

Publisher's Note Springer Nature remains neutral with regard to jurisdictional claims in published maps and institutional affiliations. 